ORAL SURGERY

\title{
Use of advanced intravenous conscious sedation techniques in complex oral surgery procedures: Comparison of midazolam, midazolam-propofol and midazolam-propofol-alfentanil combinations
}

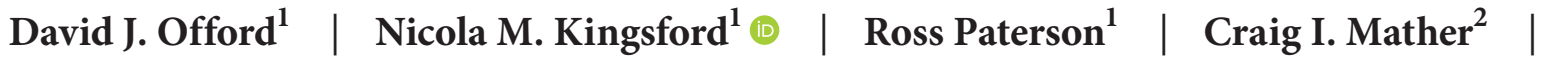 \\ Nigel D. Robb ${ }^{3}$
}

${ }^{1}$ Vermilion, Edinburgh, UK

${ }^{2}$ University of Glasgow Dental Hospital and School, Glasgow, Scotland

${ }^{3}$ School of Medicine and Dentistry, Griffith

University, Southport, QLD, Australia

Correspondence

Nicola Kingsford, Vermilion, Edinburgh, UK. Email: nicola.kingsford@vermilion.co.uk

\begin{abstract}
Aim: This retrospective observational study evaluates the safety and efficacy of intravenous sedation using midazolam only or combinations of two or three drugs including propofol and alfentanil for complex dental surgery such as implant placement or sinus augmentations.

Methods: The study analyses 60 patients aged 42-79 who required advanced sedation techniques for complex oral surgery procedures. Twenty patients had midazolam only (M), 10 patients a 2-drug combination of midazolam and propofol (MP) and a third group of 30 patients had the combination of midazolam, propofol and alfentanil (MAP). The last two regimens were carried out under the supervision of a dedicated consultant anaesthetist.

Results: Higher mean minimum heart rate (beats/min) was observed in the midazolam group compared to the group sedated with the three-drug regimen $(p<0.05)$. The time between the last drug administration (LDA) and end of surgery (EOS) was significantly longer ( $p<0.005)$ in group M ( $\leq 45$ mins) compared to the other two sedation groups MP and MAP ( $\leq 15 \mathrm{~min})$. The final titration of midazolam of $11.2 \pm 4 \mathrm{mg}(5-20 \mathrm{mg})$ was significantly greater in group M than in either of group MP or MAP $(p<0.05)$.

Conclusion: In patients requiring conscious sedation to undergo complex and lengthy oral surgery, a combination of agents (midazolam, propofol and alfentanil) can provide a predictable steady state of sedation up to the end of the surgery resulting in better operating conditions for the surgeon and improved patient co-operation. The shorter duration of action drugs propofol and alfentanil improved haemodynamic stability, sedation quality and reduce the final doses of each sedative agent.

K E Y W O R D S

alfentanil, conscious sedation, midazolam, oral surgery, propofol, triple drug combination
\end{abstract}

This is an open access article under the terms of the Creative Commons Attribution License, which permits use, distribution and reproduction in any medium, provided the original work is properly cited.

๑) 2021 The Authors. Oral Surgery published by British Association of Oral Surgeons and John Wiley \& Sons Ltd. 


\section{INTRODUCTION}

Following a report published in 2000 'A Conscious Decision', general anaesthesia for dental procedures has been restricted to hospital settings only in the United Kingdom. ${ }^{1}$ Since that time there has been an increase in the use of advanced techniques for sedation. Over the last 20 years, many advisory bodies have been involved in sedation regulation and guidelines. ${ }^{2-9}$ Attitudes towards the use of advanced sedation techniques vary widely within the dental community. Many clinicians hold the view that only the basic techniques as defined in 2007 by The Standing Committee for Sedation in Dentistry, ${ }^{8}$ i.e. titrated doses of midazolam and/or inhalation sedation with nitrous oxide should be used, and that other techniques should not be allowed within the dental practice setting.

Dental surveys have shown that over half the United Kingdom's adult population are irregular attenders due to fear, ${ }^{10-12}$ and this anxiety has increased the demand for dental conscious sedation. In addition, it has been shown that $74 \%$ of dentists in Scotland felt that there was a need for sedation in their practice. ${ }^{11-12}$

The use of advanced sedation techniques is justified where the proposed treatment is complex or lengthy in duration. ${ }^{5}$ In addition to the duration of surgery, increasingly patients are presenting aged over 65 with attendant medical co-morbidities and poly pharmacy.

Titration with small increments (top ups) of midazolam for lengthy procedures can be less predictable in terms of patient response/co-operation and surgeon satisfaction. With repeated top ups of midazolam, the sedation experience for both patient and operator diminishes as it is difficult to control the level of sedation. ${ }^{13}$

The combination of patient phobia and lengthy surgical interventions such as implant placements often in private practice settings has increased the interest in advanced sedation techniques. There is however a paucity of evidence either retrospective studies or random controlled trials on the use of advanced techniques of conscious sedation.

The intercollegiate advisory committee for sedation in dentistry (IACSD) produced a report in 2015 that set a national standard for conscious sedation in dentistry, ${ }^{9}$ this report replaced all other documents. ${ }^{2,3,6}$ The Scottish Dental Clinical Effectiveness Programme (SDCEP) has recommended that in addition to the collection of outcome measures, each provider of sedation is expected to collect person centred outcomes to inform the provision of sedation for dental care. ${ }^{5}$ Operator experience is often used as a measure of a successful advanced sedation technique as it is linked to patient experience. Optimal care should be patient centred with the focus on the individual. ${ }^{14}$

The first of the three drugs described in this study is midazolam, a water-soluble benzodiazepine sedative agent that has been in use since 1983, and this is the most widely used drug for procedural sedation. ${ }^{15-19}$ There is no pain on injection, it has rapid onset, short duration of action is a powerful anxiolytic ${ }^{16}$ and it has a wide safety margin. It is limited

\section{CLINICAL RELEVANCE}

\section{Scientific rationale}

In elderly patients requiring conscious sedation to undergo lengthy, complex oral surgery, titration with midazolam can produce less predictable patient co-operation and surgeon satisfaction. This study reports the use of a combination of agents (midazolam, propofol and alfentanil).

\section{Principal findings}

With the addition of the short acting drugs propofol and alfentanil, time between the last drug administration and end of surgery was significantly shorter ( $\leq 15 \mathrm{~min}$ ) compared to midazolam only ( $\leq 45 \mathrm{mins}$ ) and less midazolam was required.

\section{Practical implications}

The addition of shorter acting drugs provides improved operating conditions and patient experience right up to the end of surgery.

by tachyphylaxis, with the use of more of the drug resulting in less effect and can also cause paradoxical agitation and disinhibition. ${ }^{19}$ Additionally, this drug when used alone in large doses over long procedures can cause respiratory depression. $^{18}$

The second drug described is propofol. ${ }^{20-25}$ It has a rapid onset and offset. Low dose administration of propofol has also been shown to have satisfactory anxiolytic properties when used as a sedative. ${ }^{20}$ Propofol has stronger sedative effects than midazolam and because it has a narrower therapeutic window with a greater risk of respiratory and cardiovascular depression, heart function and breathing of patients need to be constantly monitored by a dedicated sedationist who has been specifically trained in advanced sedation. ${ }^{22} \mathrm{~A}$ small number of patients (20\%) experience pain on injection of propofol. ${ }^{21}$ The third sedative agent used was alfentanil administered at key moments of surgery. Alfentanil is a synthetic opioid with a rapid onset, a short duration of action and clears instantly, giving intense analgesia, with minimal cardiovascular effects. Opiates such as alfentanil are often used for their antitussive effect when used in conjunction with benzodiazepines which only provide sedation and amnesia. ${ }^{26,27}$ Alfentanil can cause respiratory depression and in higher doses it can cause bradycardia and hypotension. ${ }^{28,29}$

\section{MATERIALS AND METHODS}

This was a single centre retrospective, clinical observational study of 60 patients requiring dental procedures over a one year period. The study included patients requiring dental 
implant placement or sinus augmentation under sedation, aged $>20$ years of age and ASA between I and III. Smokers, diabetics and patients with periodontitis were not excluded and there was no restriction on opposing dentition. Surgery included full clearance, placement of four implants, three implants, sinus augmentation or a combination of these. The implant surgical procedure is described previously in detail by Offord et al $2017 .^{30}$ All patients were provided with a comprehensive and extensively written treatment plan that fully described the patient's problems and proposed treatment.

Before treatment, consent was obtained from each patient. On a consultation visit prior to surgery, an extensive sedation assessment was carried out for the proposed procedure. Weight, height, BMI and ASA grade was measured as well as the standard physiological measurements (heart rate, systolic, diastolic blood pressure and oxygen saturation) to ensure the suitability for the proposed intravenous sedation procedure. On the day of surgery, patients signed an additional consent form to confirm their continued consent to the administration of sedative drugs and the surgical procedure.

The first 20 patients were sedated with the single agent, midazolam, using the well-established single operator/sedationist model (DO) or (CM). After working in a single operator situation on 20 consecutive patients, the implant surgeons recognised the limitations of the use of this single drug regimen in complicated and long operations on elderly, polypharmacy, co-morbidity, patients in terms of operator and patient experience. Consequently, a consultant anaesthetist was invited to join the team to improve the quality of sedation. The next 10 patients were offered the dual combination of midazolam and target-controlled infusion (TCI) propofol (MP). Sedation techniques where propofol is used require a separate sedationist in order to not contravene UK standards as specified by the IACSD ${ }^{9}$ and SDCEP. ${ }^{5}$ Initially the dual combination of midazolam and TCI propofol was used until the clinic had completed the formalities to store and use Schedule 2 controlled drugs. Having reviewed the range of techniques available, a combination of midazolam, alfentanil and TCI propofol was selected. Once the clinic had the registered requirements to hold alfentanil, the next 30 patients were given the triple combination of drugs, midazolam, alfentanil and propofol (MAP) under the supervision of a dedicated consultant anaesthetist (RP).

Venous access was achieved in the dorsum hand or antecubital fossa. The heart rate (bpm), systolic and diastolic blood pressure $(\mathrm{mmHg})$ and arterial oxygen saturation $\left(\mathrm{SaO}_{2} \%\right)$ were measured prior to administration of sedative agents. Vital signs were monitored continuously using a vital sign monitor (Welch Allyn, vital sign monitor 6000). Arterial oxygen saturation $\left(\mathrm{SaO}_{2} \%\right)$ was obtained by a sensor clipped to the finger of the patient (Nellcor, Adult $\mathrm{S}_{\mathrm{p}} \mathrm{O}_{2}$ reusable sensor). Any administrator-perceived complications including apnoea, bradycardia or tachycardia and coughing were recorded. The intraoperative sedationist's satisfaction was recorded at the end of the procedure on a 6-point scale Table 1. Patient co-operation scores were measured by a sedationist on a four-point scale, Table 2.
TA B LE 1 Sedation quality scores were obtained on a 6-point scale

\begin{tabular}{ll}
\hline Score & Criteria for scoring sedation level \\
\hline 1 & Awake and anxious \\
2 & Awake and not anxious \\
3 & Speech slurred/ptosis/eve's sign \\
4 & Eyes closed and responds to speech \\
5 & Eyes closed, responds to mild stimulation \\
6 & Unresponsive to mild stimulation \\
\hline
\end{tabular}

TA B LE 2 Patient co-operation scores were obtained on a four-point scale (1-4).

\begin{tabular}{ll}
\hline Score & $\begin{array}{l}\text { Criteria for scoring patient co-operation/surgical } \\
\text { conditions }\end{array}$ \\
\hline Good & Optimum sedation, patient fully co-operative \\
Fair & Minimal interference from patient \\
Poor & Operating difficult due to over/under sedation \\
Impossible & Operating impossible due to over/under-sedation \\
\hline
\end{tabular}

\section{Drug administration}

In sedation group $\mathrm{M}$, midazolam was administered to patients with a well-documented method known as 'titration', whereby an initial titrated intravenous dose of 1-2 mg midazolam $\left(1 \mathrm{mg} \mathrm{ml}^{-1}\right)$ was administered and once the patient was calm, compliant and adequately sedated the operator could begin the procedure. Then at varying intervals additional increments of $1-2 \mathrm{mg}$ were administered as required in response to the patient's behaviour. If the operator had a sense that the patient was too alert and becoming restless, giving the impression they were not comfortable an additional increment was administered. No fixed dosage of midazolam was used. In this group of patients, the operator/ surgeon had to estimate the length of time required to finish the surgery and stop additional increments of midazolam 30-40 min from the end of surgery.

Sedation group MP was administered with midazolam in an initial bolus of $1 \mathrm{mg}\left(1 \mathrm{mg} \mathrm{ml}^{-1}\right)$ with additional increments throughout the surgery as required. Immediately after the initial bolus of midazolam, TCI propofol was started with a target blood concentration of between 0.6 and $1.2 \mathrm{ug} \mathrm{ml}^{-1}$ delivered in a $10 \mathrm{mg} \mathrm{m}^{-1}$ solution with an infusion pump. The target-controlled infusion system has become a useful way to deliver a controlled infusion of a short acting drug in sub-anaesthetic doses. The patients age and weight are entered into the infusion pump software and the desired blood propofol concentration chosen. Initially, a calculated bolus is delivered to reach the selected target blood propofol concentration and because propofol has a short half-life this is followed by a continuous propofol infusion to maintain the selected concentration. This TCI propofol technique has been described for sedation for various procedures including complicated dentistry. ${ }^{21-24}$ The use of TCI propofol in addition to midazolam created a steady state of blood concentration of the drugs and a reliable steady state of sedation. 
The third sedation group received the 3-drug regimen (MAP). These patients had the additional agent alfentanil. Alfentanil (presented as $500 \mathrm{ug} \mathrm{ml}^{-1}$ solution) was diluted down to $100 \mathrm{ug} \mathrm{ml}^{-1}$ and administered in $1 \mathrm{ml}$ boluses through the intravenous cannula. The alfentanil was administered after the initial effect of midazolam and TCI propofol were monitored. Because alfentanil is a short-acting drug with a high diffusible fraction, after a single bolus injection it reaches peak effect site concentrations quickly then begins to decline. Additional 100 ug boluses were given as required, or before a clinical intervention such as injections into the palate or bone removal. The alfentanil was administered to no more than a total maximum dose of $1000 \mu \mathrm{g}$.

In the operating room, standard monitoring was instituted. For every patient, supplemental oxygen (at $2 \mathrm{Lmin}^{-1}$ ) was administered by nasal prongs. Blood pressure, heart rate and arterial oxygen saturation was recorded every $10 \mathrm{~min}-$ utes using the vital sign monitor. Sedation scores and patient cooperation scores were made at the end of the procedure by the anaesthetist or operator/ sedationist (Tables 1 and 2).

\section{Statistical analysis}

Analysis wascarried out using Analyse-It 4.0 (2017). Statistical analysis for continuous data such as age, titrations, vital signs, duration of surgery and sedation were compared using
ANOVA between groups. The non-parametric Wilcoxon Man-Whitney signed rank or Kruskal-Wallis (with more than two groups) tests were used for statistical analysis of the patient cooperation and sedation scores. The results were evaluated with significance assessed as $p<0.05$.

\section{RESULTS}

Sixty patients had treatment under sedation. Forty-three patients were female, 17 were male with a mean age of 64 years (range 42-79). Thirty-eight of the patients were ASA group I, 18 patients were ASA group II, 1 patient was ASA group III and 3 of the patients were ASA group II/III. There was no difference in the spread of ASA levels, age or gender ratio between the sedation groups. The length of the procedures undertaken ranged from $30 \mathrm{~min}$ to $3.9 \mathrm{~h}$. All vital signs (minimum and maximum systolic blood pressure, diastolic blood pressure and oxygen saturation levels) were similar in all the sedation groups apart from a significantly higher mean minimum heart rate (beats/min) in the midazolam group compared to the group sedated with the three-drug regimen $p<0.05$ (Table 3).

There was no difference in the average/mean duration of surgery between any of the sedation groups (Table 3). The time interval between the last drug administration (LDA) and the end of surgery (EOS) (hours) was measured in all

T A B LE 3 Mean and Standard deviation of Age of patients (years), length of surgery (hours), the time between the last drug administration (LDA) and end of surgery (EOS) (hours), final titrations of the three agents. The mean of minimum and maximum of vital signs and adverse events in the three drug regimens midazolam(M), midazolam and propofol (MP)and midazolam, alfentanil and propofol (MAP)

\begin{tabular}{|c|c|c|c|c|c|c|}
\hline & \multicolumn{2}{|c|}{ Midazolam (M) } & \multicolumn{2}{|c|}{ Midazolam/ Propofol (MP) } & \multicolumn{2}{|c|}{$\begin{array}{l}\text { Midazolam/Propofol/ } \\
\text { Alfentanil (MAP) }\end{array}$} \\
\hline & \multicolumn{2}{|c|}{$(\mathrm{N}=20)$} & \multicolumn{2}{|c|}{$(\mathrm{N}=10)$} & \multicolumn{2}{|c|}{$(\mathrm{N}=30)$} \\
\hline & Mean & SD & Mean & SD & Mean & SD \\
\hline Age (years) & 63.8 & 8.8 & 65.1 & 7.8 & 63.6 & 7.0 \\
\hline \multicolumn{7}{|l|}{ Final titration } \\
\hline Midazolam (mg) & $11.2^{\mathrm{b}}$ & 4.0 & 4.7 & 2.6 & 4.1 & 1.2 \\
\hline Propofol (mg) & & & 341.0 & 130.9 & 297.9 & 74.5 \\
\hline Alfentanil (ug) & & & & & 726.7 & 187.9 \\
\hline Systolic Pressure (mmHg) & 113 & 134 & 105 & 134 & 109 & 147 \\
\hline Diastolic pressure $(\mathrm{mmHg})$ & 67 & 81 & 61 & 79 & 63 & 83 \\
\hline Heart Rate (beats/min) & $78^{\mathrm{c}}$ & 92 & 70 & 87 & 65 & 82 \\
\hline Adverse events \# & 2 & & 2 & & 0 & \\
\hline \# SaO2\% drops to $90 \%$ or below & & & & & & \\
\hline
\end{tabular}

${ }^{\text {a }}$ The time between the last drug administration (LDA) and end of surgery (EOS) is higher for group M than groups MP and MAP ( $\left.p<0.005\right)$.

${ }^{\mathrm{b}}$ Final titration of midazolam (mg) was higher in group M compared to Groups MP and MAP $(p<0.05)$.

${ }^{c}$ Minimum heart rate (beats/min) in group M was higher compared to the MAP group $(p<0.05)$. 
three groups. In sedation group $M$, this interval was measured as the time (hours) between the last increment of midazolam administration and the end of surgery. In the MP and MAP groups, this interval was measured as the time between when the TCI propofol pump was switched off and the end of surgery (EOS). The time interval between the last drug administration (LDA) and the end of surgery (EOS) (hours) was significantly longer $(p<0.005)$ in group $\mathrm{M},(\leq 45 \mathrm{~min})$, compared to the other two sedation groups ( $\leq 15 \mathrm{~min}$ ) (Table 3 ). Because the half-life of midazolam is longer than the other two drugs, patients can be still sedated for 25-45 min after the last midazolam administration; hence, midazolam top-ups are stopped 30-50 min before the end of the surgical procedure in the midazolam only sedation group.

\section{Total drug doses}

\section{Midazolam}

The midazolam was administered to patients in sedation group $M$ with an intravenous initial bolus of 1-2 mg midazolam $\left(1 \mathrm{mg} \mathrm{ml}^{-1}\right)$ then used at varying intervals dependant on the patient's responses, i.e. becoming restless and giving the impression of discomfort. Additional increments (1-2 mg) of midazolam were administered in 1-2 $\mathrm{ml}$ topups never exceeding more than $1 \mathrm{mg} \mathrm{min}^{-1}$. The final total dose of midazolam including the initial bolus and additional increments given over the course of the procedure in group $\mathrm{M}$ was $11.2 \pm 4 \mathrm{mg}$ (mean $\pm \mathrm{SD}$, range of 5-20 mg) Table 3, Figure 1. The final total dose of midazolam in the MP and MAP group, respectively, was $4.7 \pm 2.6 \mathrm{mg}$ (mean $\pm \mathrm{SD}$, range of $2-8 \mathrm{mg}$ ) and $4.1 \pm 1.2 \mathrm{mg}$ (mean $\pm \mathrm{SD}$, range of $2-7 \mathrm{mg}$ ). The total dose and variation of midazolam in group $M$ was significantly greater than in either of the other two sedation groups (Figure $1 p<0.05$ ).

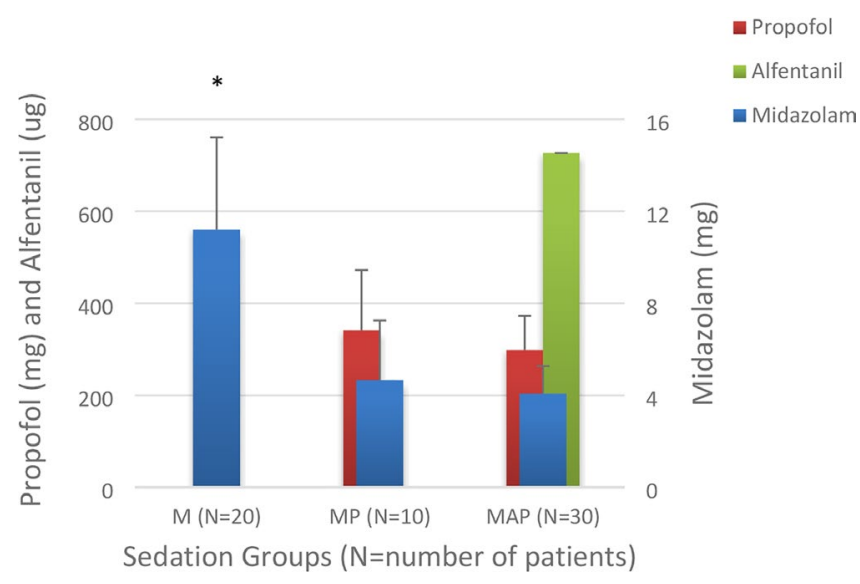

F I G U R E 1 Final titrations of midazolam (mg), propofol (mg) and alfentanil (ug) in the three sedation groups (mean +standard deviation). $\mathrm{M}$, midazolam only; MP, midazolam and propofol; MAP, midazolam, alfentanil and propofol. ${ }^{\star} p<0.05$

\section{Propofol}

The target propofol concentration required to produce satisfactory sedation quality defined by previously described end points in the MP group was $0.9 \mathrm{ug} \mathrm{ml}^{-1}$ (range 0.6-1.3 ug $\mathrm{ml}^{-1}$ ) and in the MAP group was $0.8 \mathrm{ug} \mathrm{ml}^{-1}$ (range 0.6$1.6 \mathrm{ug} \mathrm{ml}^{-1}$ ). The total dose of propofol administered over the entire procedure in the MP and MAP groups, respectively, was $341 \pm 131 \mathrm{mg}$, (mean $\pm \mathrm{SD}$, range of 250-510) and $297 \mathrm{mg} \pm 74.5 \mathrm{mg}$ (mean $\pm \mathrm{SD}$, range of $159-460 \mathrm{mg}$ ) (Figure 1, Table 3).

\section{Alfentanil}

Alfentanil was used in the MAP group at key moments during the surgery e.g. injection into the palate or bone removal. The total amount of alfentanil administered during the duration of the procedure in this group was $727 \pm 188 \mu \mathrm{g}$, (mean $\pm \mathrm{SD}$, range 400-1000 $\mu \mathrm{g}$ ) (Figure 1, Table 3).

\section{Staff Perception of sedation quality and patient co-operation.}

At the end of each procedure the intra-operative sedationist's satisfaction was recorded. Sedation quality scores were obtained on a 6-point scale (Table 1, Figure 2) and patient co-operation scores were measured on a four-point scale (Table 2, Figure 3). NB. Sedation quality and patient cooperation were not recorded in 5 and 9, respectively, of the group $M$ patients and in 1 and 1 respectively of the group MAP patients.

\section{Sedation quality}

In the midazolam group, $14 \%$ and $73 \%$ of patients scored a sedation quality of 3 or 4 respectively and $13 \%$ had a score of 2 (Table 1, Figure 2). In the midazolam/propofol group 100\% of patients in this group had a sedation quality score 4 . In the 3 -drug regimen, $96 \%$ of patients had a sedation quality score of either $3(34 \%)$ or $4(62 \%)$. The distributions of the two groups MP and MAP were significantly different $(p<0.05$, Wilcoxon- Mann-Whitney).

\section{Patient co-operation}

The patient co-operation, graded by the surgeon, was described in the midazolam only group as good in $36 \%$ and fair in 64\%, none were poor or impossible (Table 2, Figure 3). In the midazolam/propofol sedation group, the patient cooperation was described by the sedationist as 'Good' in 70\% of the patients and fair in $30 \%$. In the 3 -drug regimen, the patient cooperation was described by the sedationist as 'Good' in $83 \%$ of the patients, 'fair' in 10\%, 'poor' in 2 of the 
Staff perception of sedation quality from the three sedation groups midazolam (M), midazolam and propofol (MP), and midazolam, propofol and alfentanil (MAP)

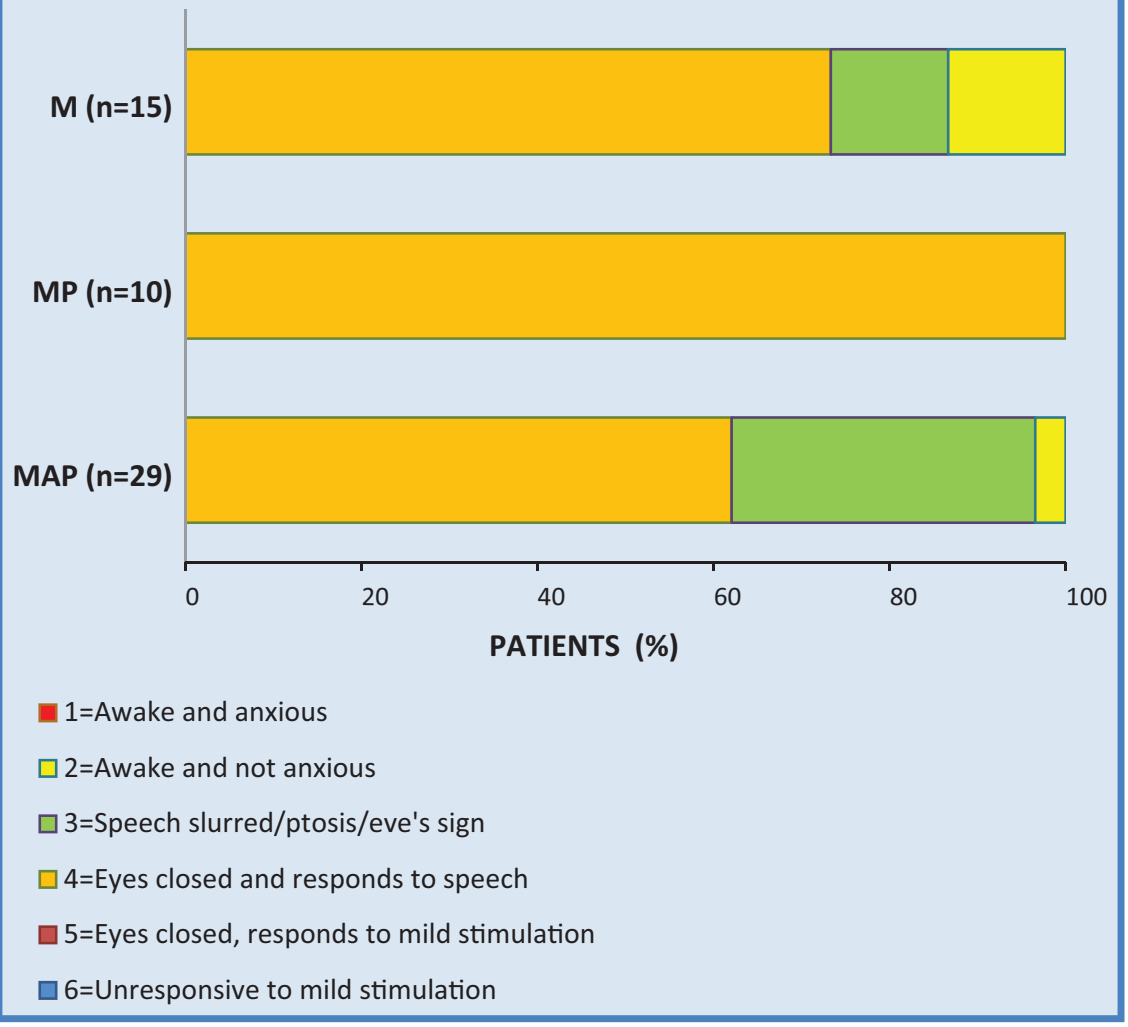

F IG U RE 2 Percentage of patients within each category of staff perception of sedation quality (1-6) in three sedation groups: midazolam (M) midazolam and propofol (MP) midazolam, propofol and alfentanil (MAP). Distribution of MAP is significantly different from MP $(p<0.05$, Wilcoxon-MannWhitney)
Staff perception of patient co-operation throughout surgery in the three sedation groups (M, MP and MAP)

$M(n=11)$

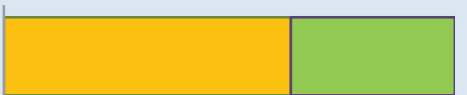

$\operatorname{MP}(n=10)$

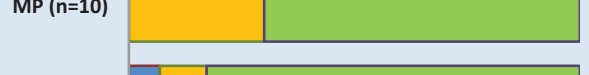

$\operatorname{MAP}(n=29)$

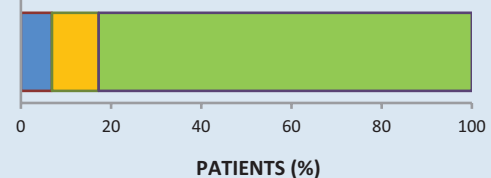

Impossible

PATIENTS (\%)

$\square$ Poor

$\square$ Fair

$\square$ Good

F I G URE 3 Percentage of patients within each category of the staff perception of patient co-operation (impossible, poor, fair and good) in the three sedation groups (midazolam (M), midazolam and propofol (MP) and midazolam, propofol and alfentanil (MAP)). Distribution of MAP is significantly different from $\mathrm{M}(p<0.05$, Wilcoxon-Mann-Whitney)

patients and none were 'impossible' (Figure 3). Statistically the distributions of the two groups M and MAP were significantly different ( $p<0.05$, Wilcoxon- Mann-Whitney).

\section{DISCUSSION}

Historically very little is reported on the combination of the three drugs midazolam, propofol and alfentanil used together for sedation in order to carry out minor procedures. In a randomised double-blind trial, McHardy et al. 2000 recruited 82 patients for a comparison of the three sedative agents together for outpatient intra-ocular surgery. ${ }^{29}$ In that study, it was demonstrated that the addition of alfentanil to the other two drugs as a sedative was advantageous as part of a sedative regimen for patients needing short procedures. Vinjk et al. $1994^{32}$ reported on PropofolMidazolam-Alfentanil combination as a triple anaesthetic. They assessed the hypnotic effects of propofol, midazolam, alfentanil, and their binary and triple combinations in 130 un-premedicated patients in a randomised control trial. Interestingly, the results indicate that the propofolmidazolam-alfentanil interaction did not significantly produce a different hypnotic effect from that of the use of the double drug regimen, the midazolam-alfentanil combination. In the past, concerns over the use of propofol centre around the high adverse event rates reported in the literature and are often attributed to very high doses. Blayney et al. $2003^{33}$ investigated target-controlled infusions (TCI) of propofol in dental procedures and reported an adverse event rate of nearly $10 \%$. The target concentration of propofol was high at $2.1 \mathrm{ug} / \mathrm{ml}$, nearly three times greater than 
the concentration used in this study. They concluded that propofol does not demonstrate the margin of safety required to satisfy the General Dental Council definition of a sedative agent suitable for use by dentists. Another comparison of the use of propofol and midazolam for use of conscious sedation in an emergency department in the Netherlands by Lemeijer et al. $2017^{34}$ showed that propofol had a greater procedural success than midazolam $(92 \%$ vs. $81 \%$ ). Propofol also had a faster recovery time; however, within the propofol group, there was a higher respiratory adverse event rate of $18.9 \%$ compared to $10 \%$ in the midazolam sedated group again; this was using a very high dose of propofol (median dose of $75 \mathrm{mg}, \mathrm{N}=284$ patients). Sato et al. $(2019)^{35}$ reported low dose bolus of propofol for gastrointestinal endoscopies in a large-scale study $(\mathrm{N}=10,662)$. They describe a low desaturation level and rapid patient recovery ( $\leq 60 \mathrm{~min}$ ). Ninety-two percent of these patients felt well enough to drive home after the procedure.

A recent paper reports on the increasing number of procedures performed in the out-of-operating room setting under sedation. ${ }^{36}$ Their sedation techniques were used for various procedures in dentistry and endoscopy aimed to achieve rapid patient turnover through the use of short-acting drugs with minimal residual side-effects (mainly propofol and opioids). Target-controlled infusions using propofol and other short-acting opioids resulted in good outcomes in terms of operator and patient satisfaction, less respiratory depression and faster recovery times. TCI propofol systems can titrate drug doses automatically to maintain optimal depth of sedation. With the addition of alfentanil to TCI propofol it is possible to further reduce the propofol dose. Although, in this study less propofol was used with the addition of alfentanil, the difference in total doses of propofol in the two groups (MP and MAP) was small and not statistically significant.

The use of advanced conscious sedation is justified in our procedures because of the duration of the procedure, age of the patients, their associated co-morbidities and often polypharmacy (duration and age reasons detailed by SDCEP for the use of advanced techniques ${ }^{5}$ ). These patients require a combination of sedation, amnesia and analgesia.

The rationale behind the use of the three-drug combination is midazolam provides the amnesic component, propofol provides the hypnotic effect and alfentanil provides the analgesia. Our results show a reliable level of sedation with all three drug regimens. With the use of midazolam alone, the surgeons noticed the patients became restless and top-ups of midazolam did not always allow optimal operating conditions. The patient may not be so amenable to co-operation on command as increased amounts of midazolam are used during lengthy surgeries. With the use of midazolam only the titration dose average was $11.2 \mathrm{mg}$, and in one case was as high as $15 \mathrm{mg}$ which is substantially higher than that detailed by the $\mathrm{BNF}^{38}$ Once higher doses are given in an invasive procedure lasting $2-3 \mathrm{~h}$, the quality of sedation diminishes. This is reflected by the higher percentage of patients scored as fair compared to the other two regimens for the surgeon's perception of patient co-operation.
The other limitation to the use of midazolam alone was the operator/surgeon required to estimate the length of time required to finish the surgery and stop additional increments of midazolam 30-40 min from the end of surgery.

Advantages were achieved with the addition of the short acting drugs propofol and alfentanil. These drugs are more titratable and therefore have a predictable effect; a steady state of blood concentration was created and thus a reliable steady state of sedation. Of the three drugs used here, propofol has the shortest half-life of 30-60 min, midazolam 90 to $150 \mathrm{~min}$ and alfentanil has an elimination half-life of $90-111$ min. $^{28}$

Although propofol has a shorter half-life the speed of recovery is determined by the redistribution of the drug. This is better described by context-sensitive half-time which is influenced by duration of infusion. ${ }^{31}$ Using drugs with shorter duration of action provides the advantage that sedation could be kept to the required level right up to the end of the procedure without the operator having to guess the endpoint. The shorter duration of action drugs improved haemodynamic stability and sedation quality and meant less midazolam was required (Figure 1), allowing for a shorter interval between the last drug administration and the end of surgery and improved patient co-operation (Table 3, Figure 3).

Although a sedation score of 2 is consistent with the definition of sedation, the ideal score in these lengthy and complex procedures is a sedation quality score of 3 or 4 (orange or green, Figure 2) and patient co-operation of 1 (good) (green, Figure 3). Sedation scores of 2 (awake and not anxious) mean the patient is not as sedated, not as comfortable, which in turn affects the surgeon's ability to focus on the procedure. When the sedation scores and patient cooperation are considered together, we see MP and MAP groups had most of the scores in the orange and green and are the best regimen for both the operator and the patient with regard to sedation quality and patient cooperation.

The biggest reported barrier to operator experience is patient coughing. Patient coughing is increased by over sedation and particularly in operations in the maxilla. ${ }^{39}$ The coughing seen in these patients is not because of contamination of the airway with secretion or debris but the 'urge to cough' which is now well documented as an index of sensation related to $\operatorname{cough}^{40}$ and we have found coughing can be reduced considerably by the addition of alfentanil without putting the patient at risk. By adding the analgesic drug alfentanil, this allows more sparing use of midazolam and propofol which allows the patient to cooperate fully and remain calm and operator conditions improve.

In some countries capnography is required for respiratory monitoring of patients undergoing conscious sedation but the guidance in the UK states that it is an emerging standard. Note that capnography was not used in this cohort of patients; but some if they choose to reproduce our work may be bound by different geographical regulations or feel more comfortable using capnography. Capnography may be most useful in patients at highest risk of over sedation; the frail, 
the elderly and those receiving potent sedatives. However, capnography should not be seen as a depth of sedation monitor. The detection of over-sedation should primarily still be by maintaining verbal communication as we have described and demonstrated in this study. In conclusion, in patients requiring conscious sedation to undergo complex and lengthy oral surgery, using a combination of agents (midazolam, propofol and alfentanil) rather than the use of midazolam alone, can provide a predictable steady state of sedation right up to the end of the surgery, resulting in better operating conditions for the surgeon and improved patient cooperation. Due to the retrospective design of this study the conclusions have to be interpreted with caution and further research is required in this area.

\section{CONFLICT OF INTEREST}

There are no conflicts of interest.

\section{ORCID}

Nicola M. Kingsford (10 https://orcid. org/0000-0003-1273-1655

\section{REFERENCES}

1. Pike D. A conscious decision. A review of the use of general anaesthesia and conscious sedation in primary dental care. SAAD Dig. 2000;17:13-4.

2. Standing Dental Advisory Committee (SDAC) Conscious sedation in the provision of dental care. Report of an Expert Group on Sedation for Dentistry. 2003.

3. Scottish Dental Effectiveness Programme Conscious sedation in dentistry, 2nd ed. June 2012. Online article available at https://www. dental-referrals.org/wp-content/uploads/2015/09/SDCEP-Consc ious-Sedation-2nd-Ed.pdf (accessed 29 Apr 2019).

4. Safe Sedation Practice for Healthcare Procedures: Standards and Guidance - Academy of Medical Royal Colleges Implementing and Ensuring Safe Sedation Practice for Healthcare Procedures in Adults. London: Academy of Medical Colleges and their Faculties; 2001.

5. Scottish Dental Effectiveness Programme Conscious sedation in dentistry, 3rd ed. June 2017. Online article available at http://www.sdcep. org.uk/wp-content/uploads/2018/07/SDCEP-Conscious-SedationGuidance.pdf (accessed 29 Apr 2019).

6. The Dental Sedation Teachers Group. Training in Conscious Sedation for Dentistry. 2007. Online article available at www.dstg.co.uk/docum ents/ (accessed 29 April 2019).

7. Faculty of Dental Surgery, Royal College of Surgeons of England Standards for Conscious Sedation in Dentistry: Alternative Techniques. London: FDS RCS(Eng). 2007. http://www.rcseng.ac.uk/ fds (accessed 19 Nov 2021)

8. Standards for Conscious Sedation in Dentistry: Alternative Techniques. A Report from the Standing Committee on Sedation for Dentistry. Faculty of Dental Surgery of the Royal College of Surgeons of England. 2007. Online article available at https://dentallawandeth ics.co.uk/wp-content/uploads/2016/03/RCS-standards-for-consc ious-sedation-in-dentistry.pdf (accessed 29 Apr 2019).

9. Standards for Conscious Sedation in the Provision of Dental Care. Report of the Intercollegiate Advisory Committee for Sedation in Dentistry. The dental faculties of the royal colleges of surgeons and the Royal College of Anaesthetists 2015. Online available at http:// www.saad.org.uk/images/Linked-IACSD-2015.pdf (accessed Feb 2020).

10. Steele J, O'Sullivan I. Executive summary: Adult dental health survey 2009. The Health and Social Care Information Centre. 2011. Online available at http://digital.nhs.uk/catalogue/PUB01086 (accessed April 2019).
11. Adult Dental Health Survey. Oral Health in the United Kingdom 1998. London: The Stationery Office; 2000.

12. Foley J. The way forward for dental sedation and primary care? $\mathrm{Br}$ Dent J. 2002;193:161-4

13. Craig DC, Boyle CA, Fleming GJ, Palmer P. A sedation technique for implant and periodontal surgery. J Clin Periodont. 2000;27(12):955-9.

14. González-Lemonnier S, Bovaira-Forner M, Peñarrocha-Diago M, Peñarrocha-Oltra D. Relationship between preoperative anxiety and postoperative satisfaction in dental implant surgery with intravenous conscious sedation. Med Oral Patol Oral Cir Bucal. 2010;15:379-82.

15. Ellis S. Response to intravenous midazolam sedation in general dental practice. Br Dent J. 1996;180:417-20.

16. Leitch JA, Anderson K, Gambhir S, Millar K, Robb ND, McHugh $\mathrm{S}$, et al. A partially blinded randomised controlled trial of patientmaintained propofol sedation and operator-controlled midazolam sedation in third molar extractions. Anaesthesia. 2004;59:853-60.

17. Tyagi P, Tyagi S, Jain A. Sedative effects of oral midazolam, intravenous midazolam and oral diazepam in the dental treatment of children. J Clin Pediatr Dent. 2013;37:301-5.

18. Qadeer MA, Lopez R, Dumot J, Vargo J. Risk factors for hypoxemia during ambulatory gastrointestinal endoscopy in ASA I-II patients. Dig Dis Sci. 2009;54:1035-40.

19. Mancuso CE, Tanzi MG, Gabay M. Paradoxical reactions to benzodiazepines: literature review and treatment options. Pharmacotherapy. 2004;24:1177-85.

20. Smith I, Monk TG, White PF, Ding Y. Propofol infusion during regional anaesthesia: sedative, amnestic and anxiolytic properties. Anesth Analg. 1994;79:313-9.

21. Saraghi M, Badner VM, Golden LR, Hersh EV. Propofol: an overview of its risks and benefits. Compend Contin Educ Dent. 2013;34:252-8.

22. Oei-Lim VLB, Vermeulen-Cranch M, Bouvy-Berends DCE. Conscious sedation with propofol in dentistry. Br Dent J. 1991;170:340-2.

23. Leitch JA, Sutcliffe N, Kenny GNC. Patient-maintained sedation for oral surgery using a target-controlled infusion of propofol - a pilot study. Br Dent J. 2003;194:43-5.

24. Rodrigo MR, Jonsson E. Conscious sedation with propofol. Br Dent J. 1989;166(3):75-80.

25. Ruiz K, Coldwell SA, Hitchin N, Dresner-Black E. Propofol sedation in general dental practice: the first 100 patients. Dent Update. 2000;27(1):16-24

26. Lee MG, Chang YJ, Park JM, Park HY. The clinical effective dose of alfentanil for suppressing cough during emergence from desflurane anesthesia. Korean J Anesthesiol. 2011;61(4):292-6.

27. Webb AR, Doherty JF, Chester MR, Cummin A, Woodhead MA, Nanson EM, et al. Sedation for fibreoptic bronchoscopy: comparison of alfentanil with papaveretum and diazepam. Respir Med. 1989;83:213-7.

28. Morgan GE, Mikhail MS, Murray MJ. editors Non-volatile Anaesthetic Agents. In Clinical Anaesthesiology, 3rd ed. New York: Lange Medical Books/MC Grawhill Publishing Division; 2002.

29. McHardy F, Fortier J, Chung F, Krishnathas A, Marshall SI. A comparison of midazolam, alfentanil and propofol for sedation of outpatient intraocular surgery. Can J Anesth. 2000;47:211-4.

30. Offord D, Mathieson G, Kingsford N, Matthys C, Glibert M, De Bruyn H. Peri-implant health, clinical outcome and patient-centred outcomes of implant-supported overdentures in the mandible and the maxilla. Br Dent J Open. 2017;3:17017.

31. Hughes MA, Glass PSA, Jacobs JR. Context-sensitive half-time in multicompartment: pharmacokinetic models for intravenous anesthetic drugs. Anesthesiol. 1992;76(3):334-41.

32. Vinik HR, Bradley EL Jr, Kissin I. Triple anesthetic combination: propofol-midazolam-alfentanil. Anesth Analg. 1994;78:354-8.

33. Blayney MR, Ryan JD, Malins AF. Propofol target-controlled infusions for sedation - a safe technique for the non-anaesthetist? $\mathrm{Br}$ Dent J. 2003;194:450-2.

34. Lameijer H, Sikkema YT, Pol A, Bosch MGE, Beije F, Feenstra R, et al. Propofol versus midazolam for procedural sedation in the emergency department: a study on efficacy and safety. Am J Emerg Med. 2017;35(5):692-6. 
35. Sato M, Horiuchi A, Tamaki M, Ichise Y, Kajiyama M, Yamamoto $\mathrm{Y}$, et al. Safety and effectiveness of nurse-administered propofol sedation in outpatients undergoing gastrointestinal endoscopy. Clin Gastroenterol Hepatol. 2019;17(6):1098-104.

36. Horiuchi A, Nakayama Y, Hidaka N, Ichise Y, Kajiyama M, Tanaka N Low-dose propofol sedation for diagnostic esophagogastroduodenoscopy: results in 10,662 adults. Am J Gastroenterol. 2009;104:1650-5.

37. Singh PM, Borle A, Goudra BG. Use of computer-assisted drug therapy outside the operating room. Curr Opin Anaesthesiol. 2016;29(4):506-11.

38. BNF Information available online at http://bnfc.nice.org.uk/drug/ midazolam.html (accessed 19 Nov 2021).

39. Hanamoto H, Sugimura M, Morimoto Y, Kudo C, Boku A, Niwa H. Cough reflex under intravenous sedation during dental implant surgery is more frequent during procedures in the maxillary anterior region. J Oral Maxillofac Surg. 2013;71(4):158-63.
40. Bolser DC. Pharmacologic management of cough. Otolaryngol Clin North Am. 2010;43(1):147-55.

How to cite this article: Offord DJ, Kingsford NM, Paterson R, Mather CI, Robb ND. Use of advanced intravenous conscious sedation techniques in complex oral surgery procedures: Comparison of midazolam, midazolam-propofol and midazolam-propofolalfentanil combinations. Oral Surg. 2021;00:1-9. https://doi.org/10.1111/ors.12688 